\title{
PRODUCING GLOBAL MALAYSIAN SECONDARY STUDENTS THROUGH FOREIGN NOVELS: CHALLENGES
}

\author{
Tan Yuet Zhou \\ Faculty of Education, Universiti Kebangsaan Malaysia, Bangi, Selangor, Malaysia \\ Email: tanyuetzhou@gmail.com \\ Azlina Abdul Aziz \\ Faculty of Education, Universiti Kebangsaan Malaysia, Bangi, Selangor, Malaysia \\ Email: azlina1@ukm.edu.my
}

\begin{abstract}
APA Citation: Tan, Y. Z, \& Aziz, A. A. (2019). Producing global Malaysian secondary students through foreign novels: Challenges. Indonesian EFL Journal, 5(2), 31-40. doi: 10.25134/ieflj.v5i2.1798.
\end{abstract}

Received: 14-03-2019

Accepted: 23-05-2019

Published: 01-07-2019

\begin{abstract}
The study of literature provides a civilizing effect on a society anywhere around the world. Through these English kinds of literature, there are aspects of English culture encapsulated in it. This could potentially help students to develop as global citizens, which understand not only the feelings, settings, culture and even thoughts conveyed through the literature but being able to apply it to the real world, as a global citizen. If young students are not able to get such valuable exposure in schools, where are they supposed to receive such valuable input? Through this study, it is aimed to provide an overview of how foreign literature English novels chosen by the Ministry of Education has expanded the students' perspective as a global citizen. This paper aimed to reveal the challenges faced by teachers in using these texts in completing the objectives of producing students as global citizens. Thus, by applying Louise Rosenblatt Transactional Theory, it scaffolds this study to examine the challenges faced by English teachers in incorporating global citizenship values through the teaching of foreign novels in English. Data was collected via classroom observations, document analysis and interviews on both teachers and students. The data collected from the interviews, observations and item analysis were analyzed and results were conveyed in different themes, on the challenges faced by the respondents.
\end{abstract}

Keywords: ESL; global citizenship; literature learning; schools; transactional theory; challenges

\section{INTRODUCTION}

According to the Malaysian secondary school syllabus, the literature component is added to the curriculum for Form 1 to Form 5 students to learn English. This has allowed Malaysian secondary school students to be engaged in the wider reading of the good literary novel, poetry, and plays for their self-enjoyment and development. Through this syllabus, it is hoped that students will be able to develop an understanding of other studies, cultures, values and even traditions that will enhance their life-long learning emotionally and spiritually. Such learning values, characteristics and input are aligned with the learning of producing global citizens.
In contrast to the beliefs conveyed previously, Malaysian secondary school students, especially second or foreign English language learners are often intimidated and scared of the idea of learning literature in the English classrooms. One of the biggest issues is that Malaysian curriculum emphasis on learning language through literature rather than developing global citizens out of the students while learning different cultures and values from the literary works. Collie and Slater (2004) conveyed that literature should be utilized in the English language classroom to not only provide valuable authentic evidence and input from literary works read but also to 
encourage personal engagement of the students while enriching the cultural and linguistic apparatus of the reader. Thus, to achieve this, Malaysian teachers are required to make use of any relevant and interesting course material that they are provided or by finding resources, printed or online, to ensure the active participation of the learners by way of activities and a strong amalgamation of language and literature.

This paper explores the challenges faced by English teachers in incorporating global citizenship values through the teaching of foreign novels in English. To scaffold this study, a research question was applied: What are the challenges faced by English teachers in incorporating global citizenship values through the teaching of foreign novels in English?

According to Rosenblatt (2005), a transaction process is determined by a reader's stance that allowed the reader to maintain their focus on their experience of reading the text. She claimed that this type of stance is required as it allows the readers to imagine and enter into a whole new world of the story from reading fiction and poetry and try to live through the moment of the world personally and experience the emotion incited.

Rosenblatt too stated that transactions between readers, texts and also the teachers are encouraged by the personal response, reflection, discussion, and elaboration. However, this is only made possible if teachers are committed to listen and view students' personal response as a crucial factor when students are engaged with the text. She conveyed that "the teacher needs to maintain the conviction that it is important to place the discussion of the text in this matrix of personal response" (1994, p. 68). Thus, instead of asking students to memorise the needed information from the poems or novels for specific purposes like examinations, that are widely done in Malaysian secondary schools, she stated that through the transactional theory, teachers must emphasis on allowing the readers to make sense of the texts, along with a discussion of the content of the texts in the classroom.

As for today, with global engagement in every part of the world, people are forming, and being identified as, global citizens that create a sense of belonging to a world community. This was made possible due to the forces of modern information, communications and transportation technologies that are increasingly relevant in today's society (De Andreotti, 2014). By increasing world connectivity with the presence of these technologies such as the creation of the Internet, it will enable people to connect to any part of the world. This has allowed the participation of global economy, worldwide environmental factors, the feeling of empathy due to pictures and videos of humanitarian disasters in other countries or even just by creating spaces for today's society to travel around the world (Jewett, 2011; Martin, Smolen, Oswald, \& Milam, 2012).

To the people who viewed themselves as global citizens, they are not abandoning their own national or individual identities, ethnicities or political beliefs. These new beliefs and values can give new meaning to those who viewed themselves as global citizens, and they will continue to shape that they eventually turn out to be (Smolen \& Martin, 2011).

Global citizenship education is a problematic term to be defined and is normally used without making sure of the difference. The research literature on the topic is divided as while some argued that global citizenship education is a moral endeavor, some other researchers view it as a set of skills, such as ICT competence (Purnell, 2002). According to Oxfam (1997), a global citizen is someone who: "... knows how the world works, is outraged by injustice and who is both willing and enabled to take action to meet this global challenge" (Oxfam, 1997, p.1)

Through the teaching of the set of skills in global education, researchers stated that the values and attitude will enable young people to critically engage with global issues and act 
for change if needed. It is essential for the development of global citizenship as knowledge, skills and understandings to challenge social injustices and inequity, actively engage in peacebuilding and cooperation to resolve conflict, respect and value diversity, commit to sustainable development and concern for the environment, and acknowledge globalization and the interdependence of political, social, economic and cultural issues are some of the few factors that allow teenagers to grow as global citizen (Meadows, 1991).

Every school plays a role in citizenship education, making it one of the most critical providers of global citizenship education. As schools have the potential to be aligned with transnational efforts that promote global civility (Reimers, 2006), the role of teachers can hardly be overstated. However, as research conveys, teachers are mostly oblivious to the purposes, methods, and content of global citizenship education. For example, out of over 700 teachers in England who rated education for global citizenship as important, only a few were confident of their ability to teach it (Falk, 1993). Overall passive, and in many cases, skeptical, attitudes to global citizenship and related concepts eventually have resulted in the neglect of global citizenship education in many schools around the world. The growing amount of research, particularly comparative research, demonstrates that "the traditional notion of developing democratic understanding needs to be expanded to encompass attention to decision making, controversial issues, and civic action set in multicultural and global contexts" (Hahn, 1998, p. 122).

Teachers may use novels to develop students' skills in spelling, handwriting, grammar, and punctuation. Besides that, teachers can help students in gradually improving their skills in writing as well as organizing materials into paragraphs by providing essay type tests. The questions constructed in the tests are not only factbased questions that serve as a basis of evaluating comprehension but also to develop critical thinking skills through open ended-questions (Dreyer, 2016; Yusof, Lazim \& Salehuddin, 2017). Open-ended questions can be made to allow students to predict outcomes, making comparisons and drawing conclusions. Class discussions of each novel event should comprise the main idea and supporting details, including who, what, when, where, and how. Details of various social issues such as sexual harassment and abortion, which are often an integral part of the plot, can provoke interesting debate.

According to the Malaysian secondary school syllabus, the literature component is added to the curriculum for Form 1 to Form 5 students to learn English. This has allowed Malaysian secondary school students to be engaged in the wider reading of good literary writing poetry and stories for their selfenjoyment and development. Through this syllabus, it is hoped that students will be able to develop an understanding of other studies, cultures, values and even traditions that will enhance their life-long learning emotionally and spiritually (Ganakumaran, 2003; Ganakumaran, Shahizah \& Lee, 2003). Such learning values, characteristics and input are aligned with the learning of producing global citizens.

A diverse range of texts has been offered and applied in all Malaysian secondary school curriculums. This covers British, Malaysians, Australian, Singaporean, South African and even most Asian countries work (Vethamani, 2004). Through the application of texts from all these countries, learners are expected to be able to discover and adhere to a storyline or understanding the figurative and literal meanings of poems and sonnets. This is to allow students to have their responses to the text at hand. Thus, the application of literature education in learning English in Malaysian secondary schools is meant to nurture students into global citizens by inculcating the values learned and to broaden their outlook from their own skeptical and rigid outlook of Malaysian cultures, values, and societies. 
One of the biggest barriers of Malaysian classrooms in producing global citizens through the teaching of literature is that Malaysian teachers tend to conduct examination-oriented lessons. It is common for teachers in Malaysia to focus extensively on examination purposes in English lessons, be it grammar, writing, reading or even literature. One of the prominent reasons will be at the end of secondary studying life, parents, teachers, students, scholars, and even the Ministry will tend to look at good grades. Each student will compete for a better grade each year. Lewey (1995) conveyed that the Malaysian education system is too examination-oriented. Though there may have been changes in attitude of teachers, school administration and the Ministry's attitude in viewing education as formative than summative in the recent years through the curriculum employed, teachers and students are still compelled by the examination and will teach and learn according to what will be tested in the upcoming public examinations such as SPM or PT3 examinations.

Several studies have been carried out to relate the heavy influence of examination has on the mindset of Malaysians as well as their curriculum development. According to Pillay and North (1977), they have examined the role of the topics in an integrated approach and the way it is handled in the KBSM syllabus, textbooks, and examinations. Through that research, they concluded that there was a dilemma by teachers on what to teach in the classrooms and to students due to a conflict between the official syllabus, the textbook syllabus, and the examination syllabus. In the official syllabus and the textbooks, it stresses on the topics or themes of the teacher's scheme of work. However, in the public examination, they focus more on skills and grammar.

\section{METHOD}

The design applied for the study will be a case study. According to Bhattacherjee (2012), a case study is "a method of intensively studying a phenomenon over time within its natural setting in one or a few sites." it can derive richer, more authentic, more contextualized interpretation of the phenomenon. Thus, a case study will be conducted to reveal the success of using foreign texts to mold students into global citizens. This research design will enable the study of the perception of the participants of the research to obtain detailed information on a small group of people or a specific context. This study will be divided into three phases. Classroom observations (first phase), document analysis (second phase) and interview (third phase) will be a mean of triangulation. By triangulating the data obtained from all three instruments, the study will corroborate findings across data sets and reduce the impact of potential biases that may exist in this study.

The sampling method used in this study was based on purposive sampling. The participants in this study were students from a suburban secondary school in Langkawi. This school is identified as a high performing school in Langkawi and has conducted lessons on the novel based on the requirements given by the Ministry of Education. 30 form 4 students, from upper intermediate to advanced level of proficiency, will be selected as participants for this research paper. The teacher is an English teacher from the English Language Department and has taught for 5 years on the novel used for this research. The novel used in this study will be the Elephant Man by Tim Vicary. A simple purposive sampling method will be used to select 10 respondents for the semi-structured interview.

These participants were selected based on their language proficiency and ability to convey what has their learning from the reading of the past year from 3 novels and to recall the teaching methods of teachers in teaching foreign novels. Therefore, the research would be able to get crucial data to analyze the findings received from the students and teachers. This is crucial as without being able to communicate proficiently, students may not be able to 
convey what have they learned, or any data intended by the students.

The first phases involved classroom observations of teachers re-teaching the given novels by the Ministry and to observe the communication between the students and teachers while the lesson is on-going. The objective of the classroom observations is to establish a base for the students to respond to the novels and to observe the interpersonal factors while learning a foreign text novel. The response and interactive sessions by the students within the classroom will be observed and noted.

The second phase was documented analysis of the students produced based on the study of the novel for the research. The study will draw upon multiple sources of evidence, namely the exercise worksheets of the students, presentation materials of the novel and the English teacher's record book in designing lessons and activities for the current form 3 students to be engaged in learning the novel.

The last phase was a semi-structured interview to be conducted on several selected students on their views and perspective of learning the novel. By having an interview, the study will expect a more detailed explanation of the key factors through the observations and document analysis. This allows the participants to describe their attitudes and beliefs of learning a foreign novel and extracting the teacher's opinions on the challenges of teaching the novel to the students. Burnard's framework (1991) will be adapted to generate a systematic and organized record of the issues and methods of solving the barriers from the teachers' opinions.

\section{RESULTS AND DISCUSSION \\ Challenges \\ Exam-oriented}

Students are lacking the motivation to think critically

Based on the collection data done, some students were found lacking in the motivation to think critically. Some of the students preferred to listen and read, rather than to think and speak. This is a challenge by the teacher, to encourage students to think critically and voicing it out during classroom presentations. Though the values and messages were clearly stated by the members of the group after their reading of the novel, some students chose to avoid thinking critically about the values and messages when inquired by the teacher. The teacher mentioned how students will choose the word "No or Don't Know, then spending a little time thinking critically and linking it to global events when asked." Such behaviors have led to the teacher opting for the memorization of events, messages, values of the novel, and even examples of world events linking to the values taught through the foreign novel. Through the classroom observations, some students would standstill while waiting for the more active members of the group to do the thinking and speaking during the role play and presentation of the required task.

\section{Stimulus}

According to the teacher, the stimulus to enhance the understanding of the values and lessons incorporated while learning the foreign novel is the challenge that he has to face to get the students interested in the lesson. Through classroom observations, the teacher has used pictures and videos related to the novel to capture the interest of the students. Multiple pictures of the main character of the novel were used to activate the inner feelings of the students and to prepare them for the learning process of the novel. Besides that, videos were downloaded and used by the teacher to further enhance the effectiveness of the stimuli. However, without subtitles and the lacking of good speakers in the class, the audio was made hard for the students to listen and to understand what was being explained in the video. With the constraint of basic instruments that enhance the stimuli for the incorporation of values in teaching the novel, the teacher resorted to a more teachercentered lesson, where the explanation of the stimuli was made orally by the teacher. 


\section{Time constraint}

Another challenge faced by the teacher while trying to incorporate global citizenship values through the teaching of foreign novels is a time constraint. According to the timetable of the teacher, in a single week, the teacher was given 5 periods of classes, equivalent to $175 \mathrm{mins}$. He conveyed that "with such limited time, trying to cramp all skills and lessons in a few periods of teaching and learning is impossible." The teacher too conveyed that because the lesson was cramped and hastened, some students were not able to catch up with the lesson, and later deem the lesson boring. This affected the motivation of the students to give up learning, as well as to think critically that could help promote global citizenship. Besides that, the teacher stated that "the time to prepare for lessons, such as videos, printed materials, PowerPoint slides required time." With other classes' teaching materials in need to be planned and ready, the time constraint is a huge obstacle.

\section{Different learning style}

According to the classroom observation done, designing a literature lesson for 30 students was a challenge to the teacher. Multiple types of learning strategies were implemented by the teacher to cope with the learning styles of the students and to provide a variety of lesson materials and styles during the teaching of the foreign novel. Learning styles used by the teacher are group discussions, presentations, reading aloud, answering writing questions and teachercentered lectures. Though multiple learning styles were used, the teacher stated that "not all lessons were able to satisfy the students. Some were happy to talk in group discussion, but were yawning when I started talking in lectures about the novel." He conveyed that coping with students learning style is difficult, especially when the class was a mixture of advance to intermediate students. This could severely affect the motivation to learn what was being taught by the teacher, hence influencing the cultural values and messages to be learned from the novel that could eventually lead to global citizenship.

\section{Lack of exposure}

According to the novel, the setting of the novel was in the $19^{\text {th }}$ century, in London. Due to the difference of time and country, the lack of exposure to the difference of norms and cultural practices were considered a challenge by the teacher to incorporate the global citizenship values that could be learned from the novel. The teacher stated that "though the values and lessons are universal, the ability for the students to imagine and practice the global citizenship values taught and shown from the novel could be an issue." Students were able to understand the value of the lessons and messages taught in the novel. For example, during the presentations, students were able to express and explain the moral value of sympathy that one should give to the deform main character.

However, when the teacher asked how could the value be practiced out of Malaysia, most students kept silent and were unable to provide excellent examples of how those values were practiced out of Malaysia. In the exercise books of the students, students were able to explain the value and how the values can be practiced by people. However, most examples were generally about Malaysians, and rarely the examples given were events or organizations outside of Malaysia. Thus, the lack of exposure by the students to the outside world than Malaysia is considered a challenge by the teacher in incorporating global citizenship values through the teaching of foreign novels in English lessons.

One of the biggest challenges of such deeply-rooted perceptions is how literature learning is perceived. One may argue that learning literature components such as poetry, novels and dramas are widening the mind of students in terms of global values, humanity and moral values, but in the end, Malaysian secondary school students and teachers may only learn literature for the sake of examination.

The goals of the lessons designed by the teacher may have been pinpointed, but for students, they may only learn the novel for the sake of examination. When students 
attend the novel learning classroom, their focus may entirely be on how that class may benefit them in school or public examinations. Open-minded questions, critical thinking, global event relations maybe some of the extra agenda for the class lesson, but lessons with such motives may end up with basic language enhance activities. Students are forced to memorize the memorable events of the novels; moral values, messages, and lessons are learned and memorized to avoid losing points when answering the novel literature questions in examinations.

To sum up, for novels, students will have to read the novel, not to enjoy it, but to understand the novel vividly and to be able to cramp out as much information as possible for the literature review essay they are required to answer during the examination. Thus, it is quite clear that the teaching and learning of English literature in Malaysian secondary schools are basically for examination purposes and such perceptions are the main barrier for teachers to create activities that in incorporating global citizenship values through the teaching of foreign novels in English.

One of the key motivations for English teachers in teaching students to enable their students to use the language effectively through personal, communal or professional contexts. For this study, teachers are looking into pedagogical methods of teaching into enabling students to use the language together with global values incorporated in the foreign novel. Though lesson designs, English teachers should motivate their students to explore the diverse identities, culture, and norms gained from reading the novel. Besides that, students will be able to think critically regarding their place in this world and build relationships within or outside of the classroom and country. This will foster a relationship to live positively and dynamically with the people around them. Furthermore, learning the novel will allow the cultivation of global values such as empathy, respect for diversity and the power to imagine in recognizing their standards, levels and place locally, nationally and towards the global communities. This will expand the students' thinking and horizons in developing critical literacy and so on, to a higher level of attainments of the global values acquired from the novel.

\section{Teaching approaches}

Based on the activities designed by the teacher for the students in learning the novel, the study can conclude that the teacher may have used a few teaching approaches in teaching the foreign novel while trying to incorporate global values into the learning process. According to Richards \& Rodgers (2014), it is more beneficial if teachers are aware of the approaches that may best serve the needs of ESL students when learning the literature component.

\section{The language model}

This is the most common approach used by the teacher while teaching the class the novel. According to Carter and Long (1991), this approach can be referred to as the language-based approach. This is an approach that made the learners to study the text of the novel more systematically and methodically. This allows the students to exemplify certain specific linguistics features such as both literal and figurative languages or speech styles used in the novel. Such an approach has allowed itself to the repertoire of strategies that the teacher has used. For example, prediction exercises during the presentation by the teacher in introducing the novel, summary writing of the chapters as well as a role-playing of the chapters by the students according to chapters of the novel. All activities designed and practiced in the classroom was to serve specific linguistics goals such as for examination purposes. Unfortunately, these activities disconnected the students from the literary text of the novel, allowing little engagement by the students on the global values imprinted in the novel, as all focus are purely on the linguistic practices of the students for specific purposes such as examinations.

\section{The personal growth model}

The activities that the teacher designed to integrated the Personal Growth Model. In 
this model, the activities designed and done were used to combine both the cultural model and language model, allowing the students to focus on both the language and context of the novel (Carter \& Long, 1991). Students, through this model, were able to express their opinions, feelings and they can make connections between their own cultural experiences to what was expressed in the text of the novel. Such a model was able to bring out the global values that the teacher was trying to incorporate in the learning of the foreign text. Students were able to link their experiences of the values and messages learned from the novel and expressed during presentations and novel literature review writing practices.

Besides, the activities that the teacher designed allowed most of the students to agree that the values that they have learned can be applied in and outside of the classroom, or linking themselves to a certain global group that practices certain global values. As Cadorath and Harris (1998:88) stated, the "text itself has no meaning. It only provides direction for the learner to construct the meaning from the learner's own experience." Therefore, the learning of the global values from the text takes its place when the learners were given the chance to imagine, interpret and construct the meaning and value of the text based on their own experience towards the text.

\section{CONCLUSION}

The findings of this study were critically discussed and analyzed to justify how the activities designed for the learning of that foreign novel was heavily based on language enhancement rather than developing the global citizenship values been introduced and explained by the teacher and students. Activities such as role-playing, reading aloud, writing literature reviews and even presentation should be able to convince and teach the students on the significance of the global citizenship values learned from the novel throughout the lessons. However, the activities were designed to enhance the students' language proficiency. Though the teacher stated that he tried to teach and cultivate global citizenship values throughout the lessons, the materials, activities, and teaching in the classroom speaks otherwise. Nonetheless, such actions are not entirely to be blamed on the teacher, as the motivation of the students, pressure by the Ministry, school administrations and parents on the performance of their children in the examination are immensely high. To add on, the constraints such as time, materials designs and students' learning styles play roles in determining the path of the learning.

In sum, the use of foreign novels was able to activate critical thinking and the understanding of global citizenship values incorporated in the novels, however, the learning, acquisition, and practice of the global citizenship values may be hindered by multiple factors. The cultivation of global citizenship values may be one of the objectives of the lessons, but it is subjective to all the constraints such as the pressure by external stakeholders and the motivation of the teachers and students in learning the foreign novel.

\section{REFERENCES}

Bhattacherjee, A. (2012). Social science research: Principles, methods, and practices. USF Tampa Bay: Open University Press.

Bland, J. (2015). Teaching English to young learners: Critical issues in language teaching with 3-12year-olds. London: Bloomsbury Publishing.

Burnard, P. (1991). A method of analyzing interview transcripts in qualitative research. Nurse education today, 11(6), 461-466.

Cadorath, J., \& Harris, S. (1998). Unplanned classroom language and teacher training. ELT Journal, 52(3), 188-196.

Carter, J. B. (2007). Transforming English with graphic novels: Moving toward our optimus prime. English Journal, 49-53.

Collie, J., \& Slater, S. (2004). Literature in the language classroom: A resource book of ideas and activities. London: Ernst Klett Sprachen.

de Andreotti, V. O. (2014). Soft versus critical global citizenship education: Development education in policy and practice. London: Palgrave Macmillan.

Falk, R. (1993). The making of global citizenship. In J. Brecher, J. B. Childs, \& J. Cutler (Eds.), Global visions: Beyond the new world order (pp. 39-50). Boston, MA: South End. 
Indonesian EFL Journal (IEFLJ)

Volume 5, Issue 2, July 2019

Ganakumaran, S. (2003). Literature programs in Malaysian schools: A historical overview. In S. Ganakumaran, \& M. Edwin (Eds), Teaching of Literature in ESL/EFL Contexts (pp. 27-48). Petaling Jaya: Sasbadi Sdn. Bhd.

Ganakumaran, S., Ismail, S., \& Koo, Y. L. (2003). The incorporation of the literature component. In S. Ganakumaran, \& M. Edwin (Eds), Teaching of literature in ESL/EFL contexts (pp. 62-87).

Hahn, C. (1998). Becoming political: Comparative perspectives on citizenship education. New York: Suny Press.

Jewett, P. (2011). Some people do things different from us: Exploring personal and global cultures in a first-grade classroom. The Journal of Children's Literature, 37(1), 20-29.

Khatib, M., Rezaei, S., \& Derakhshan, A. (2011). Literature in EFL/ESL classroom. English Language Teaching, 4(1), 201-208.

Martin, L. A., Smolen, L. A., Oswald, R. A., \& Milam, J. L. (2012). Preparing students for global citizenship in the twenty first century: Integrating social justice through global literature. The Social Studies 103, 158-164. doi: 10.1080/00377996.2011.601358.

Meadows, D. H. (1991). The global citizen. Washington: Island Press.

Oxfam, A. (1997). A curriculum for global citizenship. London: Oxfam GB.

Pillay, H., \& North, S. (1997). Tied to the topic: Integrating grammar and skills in KBSM. The English Teacher, 26, 1-23.

Purnell, D. (2002). The changing role of teachers in embedding ICTs into the curriculum: A case
p-ISSN 2252-7427, e-ISSN 2541-3635

https://journal.uniku.ac.id/index.php/IEFLJ/index

study in a Tasmanian school. Unpublished Dissertation. Curtin University.

Reimers, F. (2006). Citizenship, identity, and education: Examining the public purposes of schools in an age of globalization. Prospects, 36(3), 275-294.

Richards, J. C., \& Rodgers, T. S. (2014). Approaches and methods in language teaching. Cambridge: Cambridge university press.

Rosenblatt, L. (1938). Literature as exploration. New York: Appleton-Century.

Rosenblatt, L. (1978). The reader, the text, the poem: The transactional theory of the literary work. Carbondale: Southern Illinois University Press.

Rosenblatt, L. (1994). The reader, the text, the poem. Carbondale: Southern Illinois University Press.

Rosenblatt, L. (1995). Literature as exploration (5 $5^{\text {th }}$ ed.). New York: Modern Language Association.

Rosenblatt, L. (2005). Meaning-making with texts. Portsmouth, NH: Heinemann.

Smolen, L. A., \& Martin, L. (2011). Integrating global literature into the elementary social studies curriculum. The International Journal of Learning, 17(11), 183-192.

Van, T. T. M. (2009). The relevance of literary analysis to teaching literature in the EFL classroom. English Teaching Forum, 47(3), 2.

Yusof, S. M., Lazim, Z. M., \& Salehuddin, K. (2017). Teacher trainees' perspectives of teaching graphic novels to ESL primary schoolers. $3 L$ : Language, Linguistics, Literature ${ }^{\circledR}, 23(3)$, 136152. 
Tan Yuet Zhou \& Azlina Abdul Aziz

Producing global Malaysian secondary students through foreign novels: Challenges 